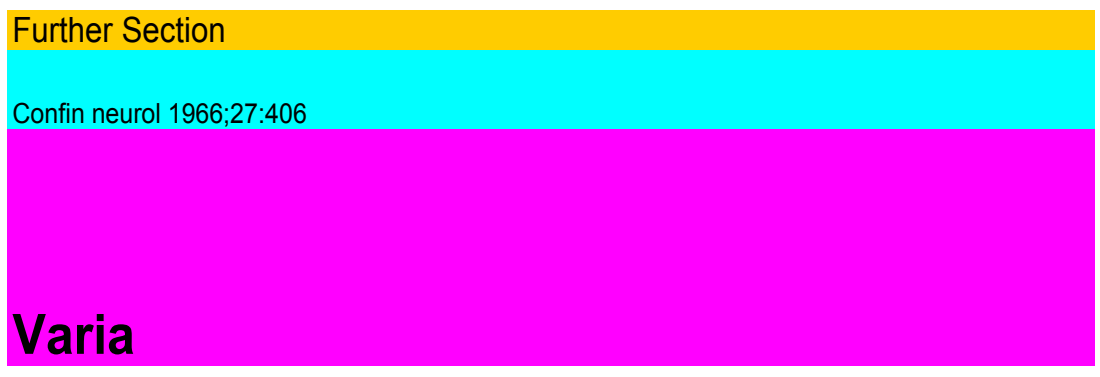

Snider, R. S. and Niemer, W. T.: A Stereotaxic Atlas of the Cat Brain. Univ. of Chicago Press, Chicago, DL, 1961.

Snider, R. S. and Lee, J. C: A Stereotaxic Atlas of the Monkey Brain. Univ. of Chicago Press, Chicago, Dl. 1961.

These two aüasses offer the advantage of not being limited to the diencephalon and forebrain ganglia but of including also the lower parts of the brain stem. Both über and cellular stains are presented from each level. Thea atlasses will be a neces-sary part of any laboratory dealing with stereotaxic work on these animals. E. S.

Emmers, R. and Akert, K.: A Stereotaxic Atlas of the Brain of the Squirrel Monkey (Saimiri sciureus). Univ. of Wisconsin Press, Madison, Wiscon, 1963. Price: S 15.00.

In view of the increased use of the squirrel monkey, this atlas containing illustrations that show both fiber and cell staining will be a welcome addition to the neurophysiologist's armanentarium.

\title{
VARIA
}

\section{Experimental Biology and Medicine}

In September 196630 scientists from 10 different countries met inValbella near Chur (Switzerland) for a Conference on Experimental Biology and Medicine. The main theme discussed by these specialists in the fields of genetics, biochemistry, biophys-ics, microbiology and virology, as well as experimental medicine, was the control mechanisms of the differentiation and the dedifferentiation of cells - the search for the chemical nature of matter which determines the development of the embryonic cells into muscle, nerve, cartilage or even Cancer cells.

The Conference, which was supported by NATO, German ministries and the Volkswagen Foundation, was initiated and organised by Professor Emmi Hagen (Bonn), Professor F. Zilliken (Marburg) and Dr. W. Wechsler (Cologne). The Conference was held under the patronage of the Publishing firm S. Karger AG (Basel) who will bring out the details report.

The results of the scientific discussions of the international Conference were so stimulating and construclive that it was decided to hold a similar Conference at the same place on two years' time to discuss further developments in research. 